\title{
Influence of Winding Patterns and Infiltration Parameters on Chemical Vapor Infiltration Behaviors of $\mathrm{SiC}_{\mathrm{f}} / \mathrm{SiC}$ Composites
}

\author{
Daejong Kim ${ }^{\dagger}$, Myoungjin Ko, Hyeon-Geun Lee, Ji Yeon Park, and Weon-Ju Kim \\ Nuclear Materials Development Division, Korea Atomic Energy Research Institute, Daejeon 305-353, Korea \\ (Received July 29, 2013; Revised September 17, 2013; Accepted September 18, 2013)
}

\section{$\mathrm{SiC}_{\mathrm{f}} / \mathrm{SiC}$ 복합체의 화학기상침착 거동에 미치는 권선 구조와 침착 변수의 영향 \\ 김대종 ${ }^{\dagger} \cdot$ 고명진 · 이현근 · 박지연 · 김원주 \\ 한국원자력연구원 원자력소재개발부 \\ (2014년 7월 29일 접수 ; 2014년 9월 17일 수정 ; 2014년 9월 18일 채택)}

\begin{abstract}
$\mathrm{SiC}$ and its composites have been considered for use as nuclear fuel cladding materials of pressurized light water reactors. In this study, a $\mathrm{SiC}_{\mathrm{f}} / \mathrm{SiC}$ composite as a constituent layer of $\mathrm{SiC}$ triplex fuel cladding was fabricated using a chemical vapor infiltration (CVI) process in which tubular $\mathrm{SiC}$ fiber preforms were prepared using a filament winding method. To enhance the matrix density of the composite layer, winding patterns, deposition temperature, and gas input ratio were controlled. Fiber arrangement and porosity were the main parameters influencing densification behaviors. Final density of the composites decreased as the SiC fiber volume fraction increased. The CVI process was optimized to densify the tubular preforms with high fiber volume fraction at a high $\mathrm{H}_{2} / \mathrm{MTS}$ ratio of 20 at $1000^{\circ} \mathrm{C}$; in this process, surface canning of the composites was effectively retarded.
\end{abstract}

Key words : Silicon carbide, Composite, Filament winding, Chemical vapor infiltration, Nuclear fuel cladding

\section{1. 서 론}

1958년 세계 최초의 가압경수로형(pressurized light water reactors)인 미국의 Shippingport 원전의 가동 이후, 현재 원 자력 발전소의 대부분을 차지하는 가압 경수형 원자로는 높은 안전 수준을 유지하기 위해 다양한 심층 방어(defense in depth) 개념이 도입되었다. ${ }^{1)}$ 다중의 물리적 방벽(multiple barrier) 중 핵심개념은 핵연료 소결체(fuel pellet), 핵연료 피복관(fuel cladding), 원자로냉각재 압력경계(reactor coolant pressure boundary, RCPB), 격납용기(containment)의 4가지 로 구성되어 있으며, 이들 중 어느 하나라도 건전성이 유 지가 되면 방사성 물질의 대량 유출은 발생하지 않는다. 핵분열 과정에서 생성되는 방사성 물질의 대부분은 1차 방벽인 핵연료 소결체에 머무르며, 핵연료 소결체로부터 빠져 나오는 핵분열 생성물은 2차 방벽인 핵연료 피복관 에 의해 냉각수로의 누출이 방지 된다. 따라서, 핵연료 피 복관은 핵분열 생성물의 외부로의 누출을 막을 수 있는

${ }^{\dagger}$ Corresponding author : Daejong Kim

E-mail : dkim@kaeri.re.kr

Tel : +82-42-868-4559 Fax : +82-42-862-8549
담지능이 우수해야 하며, 안전 개념으로 인해 희생되는 열전달과 중성자 이용효율 감소를 최소화 해야 된다. 그 러나 $\mathrm{SiC}_{\mathrm{f}} / \mathrm{SiC}$ 복합체의 경우 높은 사고저항성이 뛰어나 고 높은 강도와 우수한 중성자 조사 특성을 가지나, 많은 기공을 포함하고 있고 비교적 낮은 응력에서 $\mathrm{SiC}$ 기지상 의 균열이 발생할 수 있기 때문에 핵분열 생성물의 담지 능이 떨어진다. ${ }^{2)}$ 따라서, 핵분열 생성물의 담지능 향상을 위해 높은 밀도를 가지는 $\mathrm{CVD} \mathrm{SiC}$ 가 내층으로 증착이 된다. 또한, 장기간 안정성을 위해 고온 고압의 냉각수 환 경에서 장시간 건전성을 유지할 수 있어야 하기 때문에 부식에 의한 기계적 강도 저하가 발생하면 안된다. 따라 서, $\mathrm{SiC}_{\mathrm{f}} / \mathrm{SiC}$ 복합체 층의 보호를 위해, 약 $100 \mu \mathrm{m}$ 가량 의 $\mathrm{CVD}$ 또는 $\mathrm{CVI}$ 로 제조된 $\mathrm{SiC}$ 외층이 포함되며, 삼중 층 구조의 $\mathrm{SiC}$ 복합체 튜브가 가압경수형 원자로의 핵연 료 피복관으로 고려되고 있다. ${ }^{3)}$

핵연료 피복관은 높은 강도가 요구될 뿐만 아니라, 핵 분열 반응으로부터 발생하는 열을 냉각수로 효과적으로 전달이 되어야 하기 때문에, $\mathrm{SiC}_{\mathrm{f}} / \mathrm{SiC}$ 복합체층의 고밀도 $\mathrm{SiC}$ 기지상 채움 기술이 요구가 된다. $\mathrm{SiC}$ 기지상을 채우 는 기술은 고분자침투 열분해법(PIP, polymer impregnation and pyrolysis), 용융 실리콘 침투법(LSI, liquid silicon 
infiltration), 화학기상침착법(CVI, chemical vapor infiltration), 슬러리 침착 및 고온 가압소결법(slurry infiltration and hot press)가 대표적이다. ${ }^{4-8)} \mathrm{SiC}$ 는 화학양론비를 가지고, 불순 물의 양이 최소일 때 가장 높은 중성자 조사특성을 보이 기 때문에, 화학기상침착 및 소결조제를 최소화한 슬러리 침착법으로 제조된 $\mathrm{SiC}_{\mathrm{f}} / \mathrm{SiC}$ 복합체가 가장 우수한 중성 자 조사특성을 가지는 것으로 알려져 있다. ${ }^{9,10)}$

가압 경수형 원자로의 핵연료 피복관은 약 $0.6 \mathrm{~mm}$ 두 께의 얇은 관 형태이기 때문에 $\mathrm{SiC}$ 직조천(fabric)으로 균 일한 복합체 프리폼을 제조하기 힘들다. 따라서 필라멘트 와인딩이나 브레이딩법으로 제조를 하게 되는데, 브레이 딩 방법의 경우 섬유의 끊김이 발생하기 쉽고, 섬유 부피 분율이 필라멘트 와인딩 법에 비해 낮기 때문에 강도가 낮아 핵연료 피복관에 적용하기가 쉽지 않다. ${ }^{11)}$ 따라서 피복관용 $\mathrm{SiC}$ 복합체 튜브는 제조는 대부분 필라멘트 와 인딩법으로 이루어 지고 있다. ${ }^{3)}$ 필라멘트 와인딩법은 섬 유폭과 와인딩 길이 등의 변화에 따라 다양한 패턴들이 형성될 수 있으며 이로 인하여 섬유 부피 분율이 크게 바 뀌는 것을 나타났다. ${ }^{12)}$ 또한, 섬유 부피 분율은 복합체의 강도에 매우 큰 영향을 미치게 되고, 또한 화학기상침착 거동 역시 바뀔 수 있다. ${ }^{13-16)}$

따라서 본 연구에서는 가압경수형 원자로의 핵연료 피 복관으로 적용하기 위한 삼중층 $\mathrm{SiC}$ 복합체 튜브를 화학 기상법으로 제조하였으며, $\mathrm{SiC}_{\mathrm{f}} / \mathrm{SiC}$ 복합체 층의 밀도를 향상시키기 위해, 와인딩 패턴과 온도, 입력 기체비의 영 향에 대하여 살펴 보았다.

\section{2. 실험 방법}

삼중층 $\mathrm{SiC}$ 복합체 피복관을 제조하기 위해 $8.5 \mathrm{~mm}$ 직 경의 고순도 흑연에 약 $320 \mu \mathrm{m}$ 두께의 $\mathrm{SiC}$ 를 $\mathrm{CVD}$ 법으 로 증착한 후, $\mathrm{UBE}$ 사에서 제조된 Tyranno $\mathrm{SA} 3 \mathrm{SiC}$ 섬유 를 이용하여 필라멘트 와인딩법으로 복합체 섬유 프리폼 을 제조하였다. 원자력급 섬유로 분류되어있는 Tyranno $\mathrm{SA} 3$ 섬유는 $7.5 \mu \mathrm{m}$ 의 직경을 가지며, 섬유 다발(yarn)은 800 수(filament)로 구성되어 있다. 필라멘트 와인딩은 4축 장비(PICO Co.)를 이용하여 $9.1 \mathrm{~mm}$ 직경의 맨드릴(mandrel) 에 $0.965 \mathrm{~mm}$ 의 섬유 다발 폭(band width), $\pm 55^{\circ}$ 의 와인딩 각을 가지도록 나선형으로 섬유 프리폼을 제조하였으며, 권선 길이를 95-103 mm로 변경함으로써 섬유 와인딩 패 턴을 조절하였다. 모든 섬유 프리폼은 2층(fly)으로 제조 되었다.

$\mathrm{SiC}_{\mathrm{f}} / \mathrm{SiC}$ 복합체의 계면상인 $\mathrm{PyC}$ 와 기지상인 $\mathrm{SiC}$ 는 수 직로를 이용하여 저압에서 화학기상침착(low pressure chemical vapor infiltration, CVI)법으로 제조 되었다. 계면 상인 $\mathrm{PyC}$ 는 $1100^{\circ} \mathrm{C}$ 의 20 torr에서 $\mathrm{H}_{2}-\mathrm{CH}_{4}$ 환경에서 5 시 간 동안 증착 되었으며, 이때 계면상의 두께는 약 $200 \mathrm{~nm}$
로 측정이 되었다. $\mathrm{SiC}$ 기지상의 침착을 위해서 $\mathrm{MTS}$ (methyltrichlorosilane, $\mathrm{CH}_{3} \mathrm{SiCl}_{3}$ )를 증착 원료물질로 사용 하였으며, 운반 및 희석 기체로는 고순도 $\mathrm{H}_{2}$ (99.999\%)를 이용하였다. $1000-1050^{\circ} \mathrm{C}$ 에서 침착공정을 수행하였으며, 원료 기체에 대한 희석 기체의 비 $\left(\alpha=\mathrm{P}_{\mathrm{H} 2} / \mathrm{P}_{\mathrm{MTS}}\right)$ 가 10 20 으로 조절 하였다. 기체의 총유량은 $800 \mathrm{sccm}$, 증착 압 력은 $2.7 \mathrm{kPa}$ 이었다. 증착된 $\mathrm{SiC}$ 층의 상분석 $\mathrm{XRD}$ 를 이 용하여 분석하였으며, Raman과 XPS를 이용하여 유리 $\mathrm{SiC}$ 의 존재 유무를 분석하였다.

\section{3. 결과 및 고찰}

삼중층 $\mathrm{SiC}$ 복합체 피복관은 고밀도의 $\mathrm{CVD} \mathrm{SiC}$ 가 내 부에 코팅되어 있기 때문에 등온 등압 $\mathrm{CVI}$ 법을 이용하여 $\mathrm{SiC}_{\mathrm{f}} / \mathrm{SiC}$ 복합체 기지상을 침착하였다. Fig. 1 는 4 가지 와 인딩 패턴으로 제조된 복합체 섬유 프리폼의 CVI 거동을 보여 주고 있다. 등온 등압 CVI법은 forced CVI법에 비 해 복합체의 내부와 표면 사이에서 원료기체 물질의 농 도 구배가 크게 발생하기 때문에, 1-return과 2-return 패턴 의 경우 얇은 복합체층의 두께에도 불구하고 3 시간의 침 착 공정 시간 후에 표면 막힘 현상이 발생하였으며, 복합 체의 내부와 표면에서 $\mathrm{SiC}$ 기지상의 밀도 구배가 크게 나 타났다. 반면 6-return과 9-return 패턴의 경우 증착 초기부 터 비교적 균일한 $\mathrm{SiC}$ 기지상이 침착 되었으며, 15 시간 후 내부와 외부의 $\mathrm{SiC}$ 기지상 밀도 차이는 거의 없는 것 을 볼 수 있다. 동일한 섬유와 각도를 가지더라도, $\mathrm{SiC}$ 섬 유의 권선 형태에 따라 $\mathrm{SiC}_{\mathrm{f}} / \mathrm{SiC}$ 복합체의 침착거동의 차 이가 발생하는 것은 복합체의 섬유 부피 분율 차이에 기 인한 것으로 판단이 된다. 복합체의 부피밀도(bulk density, $\mathrm{D}_{\mathrm{b}}$ )는 섬유 권선 전후의 질량 변화 $(\Delta \mathrm{m})$ 와 $\mathrm{SiC}$ 기지상을 채 운 후 주사전자현미경(SEM)을 통해 복합체 두께를 측정하 여 아래 식 (1)과 같이 부피분율(V)로부터 계산되었다. ${ }^{12)}$

$$
\mathrm{D}_{\mathrm{b}}\left(\mathrm{g} / \mathrm{cm}^{3}\right)=\Delta \mathrm{m}(\mathrm{g}) / \mathrm{V}\left(\mathrm{cm}^{3}\right)
$$

Table 1에서 보는 바와 같이 섬유 궤적(trajectory)이 순 차적으로 권선이 된 1-return과 2-return 패턴은 약 $55 \%$ 정 도의 높은 섬유 부피 분율을 가진다. 반면, 섬유 궤적이 섬유의 다발 폭(band width)의 2 또는 3 배 간격으로 권 선된 6-return과 9-return 패턴의 경우 +55 와 $-55^{\circ}$ 섬유간 간섭으로 인해 큰 공간이 발생되어 섬유 부피 밀도가 낮 아진다. 이러한 와인딩 패턴의 차이는 원료기체가 확산해 들어가는 확산 경로의 차이를 유발한다. 1-return과 2-return 의 경우 Fig. 2에서 보는 바와 같이 치밀하게 섬유가 감 겨 있기 때문에, 섬유 다발들 사이(interbundle)의 공간이 거의 없다. 따라서 반응 기체는 섬유 다발 내부(intrabundle) 를 통해 확산하기 때문에 확산 속도가 매우 느리고, 대부 


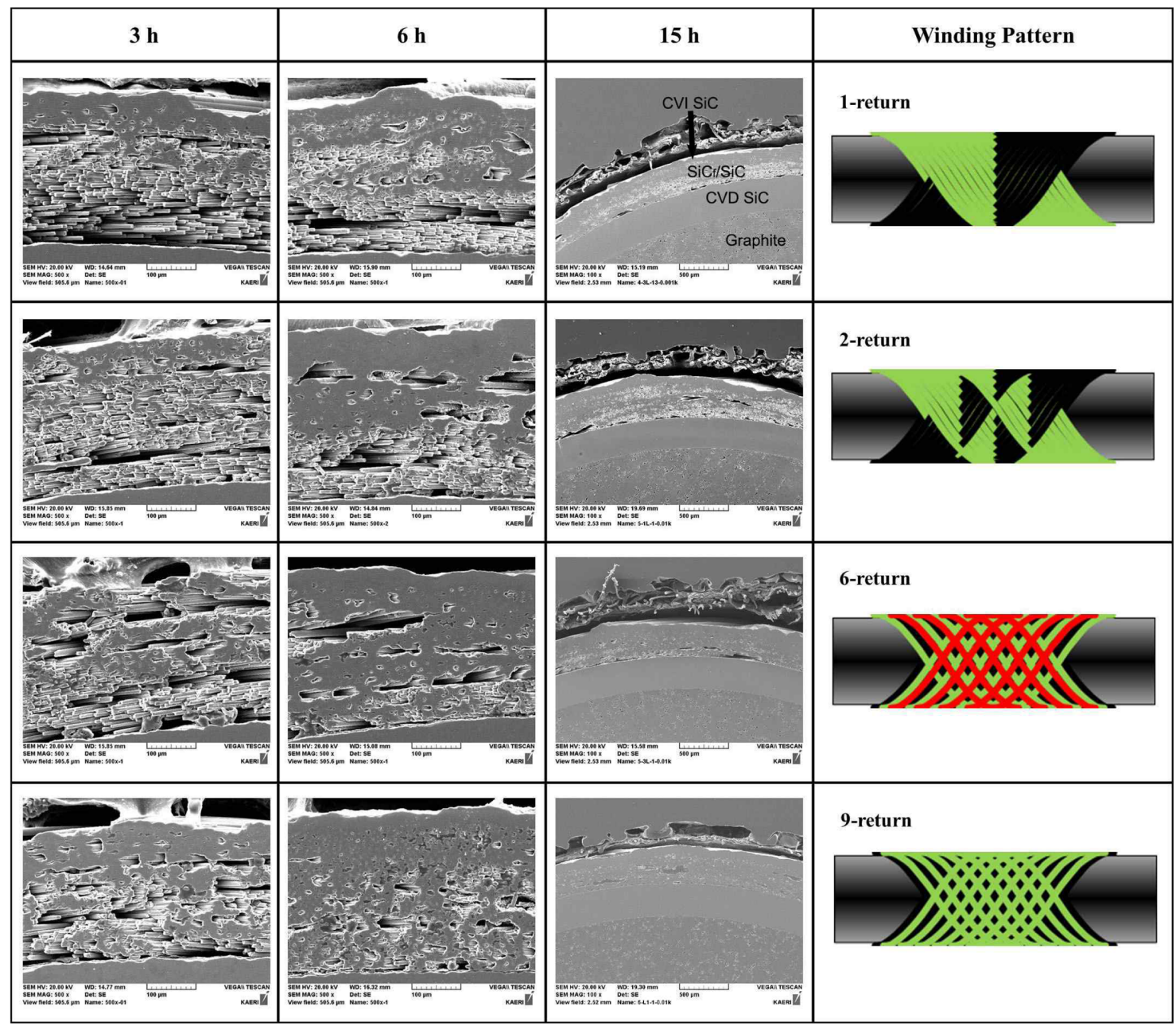

Fig. 1. Densification behaviors of $\mathrm{SiC}_{\mathrm{f}} / \mathrm{SiC}$ composites with 4 phase winding patterns during the CVI process.

Table 1. Fiber Volume Fraction of $\mathrm{SiC}_{\mathrm{f}} / \mathrm{SiC}$ Composite

\begin{tabular}{ccccc}
\hline & \multicolumn{4}{c}{ Winding pattern } \\
\cline { 2 - 5 } & 1-return & 2-return & 6-return & 9-return \\
\hline $\begin{array}{c}\text { Fiber volume } \\
\text { fraction (vol\%) }\end{array}$ & 54.5 & 54.2 & 48.1 & 45.8 \\
\hline
\end{tabular}

분의 반응이 표면에서 발생하여 반응 초기부터 표면 막 힘 현상이 발생한다. 반면 6-return과 9-return의 경우 하나 의 섬유 층(fly)를 구성하고 있는 2-3개의 단위 층들 사 이로 +55 와 $-55^{\circ}$ 가 겹치는 부분에서 들뜸이 발생한다. 따 라서 섬유 다발들간 공간을 통해 원료 기체의 확산이 용 이하여 증착 초기부터 내부까지 균일한 침착이 일어난다. 그러나 섬유 다발들 사이의 공간이 많기 때문에 섬유 다 발간 기공(interbundle pore)의 빈도수가 1-return과 2-return 에 비해 크게 높은 것을 볼 수 있다.

필라멘트 와인딩 패턴을 조절하여 $\mathrm{CVI}$ 를 이용한 $\mathrm{SiC}$ 기지상의 밀도를 향상할 수는 있으나, 경수형 핵연료 피 복관은 높은 열전도도가 요구되고 다양한 응력에 노출되

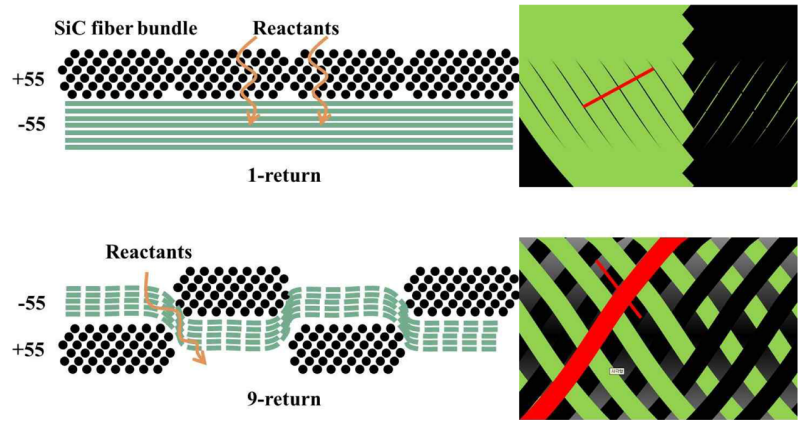

Fig. 2. Diffusion of reactants in $\mathrm{SiC}_{\mathrm{f}} / \mathrm{SiC}$ composites with 1return and 9-return winding patterns.

기 때문에 높은 강도를 가져야만 한다. 따라서 섬유 부피 분율이 높이면서 동시에 기지상의 밀도를 향상 시킬 필 요가 있다. Fig. 3은 섬유 부피 분율이 가장 높은 1-return 와인딩 패턴을 가지는 섬유 프리폼의 $\mathrm{H}_{2} / \mathrm{MTS}$ 분율의 변 화 및 온도 변화에 따른 $\mathrm{SiC}$ 삼중층 복합체의 미세구조 변화를 보여 주고 있다. $\mathrm{SiC}$ 는 일반적으로 증착 압력, 원 


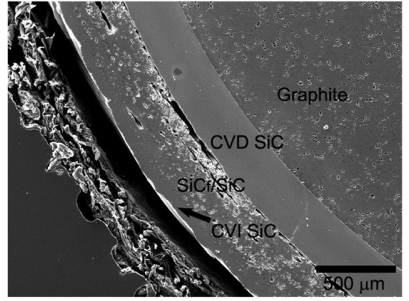

(a)

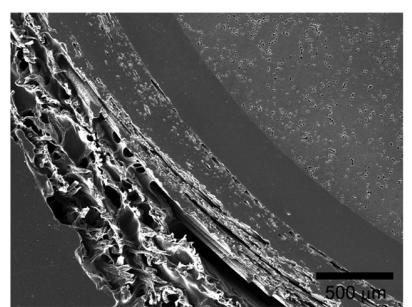

(c)

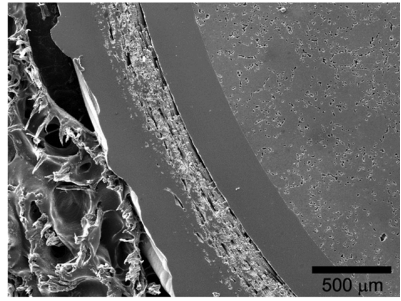

(b)

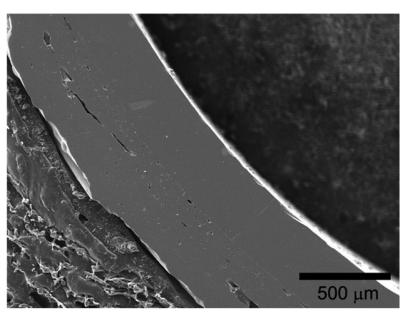

(d)
Fig. 3. Microstructure of $\mathrm{SiC}$ triplex tubes with a 1-return winding pattern deposited at: (a) $\alpha=10, \mathrm{~T}=1000^{\circ} \mathrm{C}$, $15 \mathrm{~h}$, (b) $\alpha=10, \mathrm{~T}=1050^{\circ} \mathrm{C}, 15 \mathrm{~h}$, (c) $\alpha=20$, $\mathrm{T}=1000^{\circ} \mathrm{C}, 15 \mathrm{~h}$, and (d) $\alpha=20, \mathrm{~T}=1000^{\circ} \mathrm{C}, 25 \mathrm{~h}$.

료기체비 등에 따라 달라질 수 있지만 $1000^{\circ} \mathrm{C}$ 이하의 증 착 온도에서 화학기상증착 또는 침착이 될 때, 유리 $\mathrm{Si}$ 가 형성될 수 있다고 보고되고 있다. 따라서 유리 $\mathrm{Si}$ 와 $\mathrm{C}$ 를 가지지 않는 화학양론비의 $\mathrm{SiC}$ 를 증착하기 위해서는 $1000^{\circ} \mathrm{C}$ 초과의 온도에서 증착이 되어야 한다. ${ }^{17)}$ 증착 온 도를 $1000^{\circ} \mathrm{C}$ 에서 $1050^{\circ} \mathrm{C}$ 로 높임에 따라 $\mathrm{SiC}$ 의 증착 속도 가 증가하게 되고, 표면에서의 빠른 반응 속도로 인하여 표면 막힘 현상이 $1000^{\circ} \mathrm{C}$ 에 비해 현저하게 증가하였다. 이로 인하여 15 시간 침착 후 $\mathrm{SiC}$ 외층은 약 $150 \mu \mathrm{m}$ 이 상으로 두껍게 증착이 되었다. 반면 입력기체비 (a)를 10 에서 20 으로 높일 경우 $\mathrm{H}_{2}$ 희석 기체내의 원료기체 양이 줄어들게 되어 증착 속도가 떨어지게 된다. 원료기체가 복합체 층의 내부로 확산하는데 필요한 시간이 늘어남에 따라 농도 구배가 줄어어 표면 막힘 현상은 15 시간 침착 공정 후에도 거의 발생하지 않았으며, 25 시간 침착 후 기 지상의 밀도 구배가 없는 고밀도의 복합체를 제조 할 수 있었다.

Fig. 4 는 $1000^{\circ} \mathrm{C}, \alpha=10$ 의 조건에서 증착된 $\mathrm{SiC}$ 기지상 의 XRD 및 XPS 분석 결과를 보여 주고 있다. XRD 분 석 결과에서 볼 수 있듯이 침착된 $\mathrm{SiC}$ 기지상은 (111) 우 선 배향면을 가지는 순수한 $\beta-\mathrm{SiC}$ 로 나타났다. XPS 분석 결과에서도 $\mathrm{SiC}$ 에 해당하는 $100.5 \mathrm{eV}$ 의 결합에너지를 가 지는 $\mathrm{Si}-\mathrm{C}$ 결합의 $\mathrm{Si} 2 \mathrm{p}_{1 / 2,3 / 2}$ 피크와 native oxide인 비화 학양론의 $\mathrm{SiO}_{\mathrm{x}} \mathrm{C}_{\mathrm{y}}$ 및 $\mathrm{SiO}_{2}$ 에 해당하는 $102.2 \mathrm{eV}$ 와 $103.2 \mathrm{eV}$ 에서 $\mathrm{Si}$ 피크가 관찰되고 있다. ${ }^{18)}$ 유리 $\mathrm{Si}$ 의 경우 $\mathrm{Si}-\mathrm{Si}$ 결 합에너지는 $99.5 \mathrm{eV}$ 이며, 침착된 $\mathrm{SiC}$ 의 XPS 스펙트럼에 서는 관찰이 되지 않는다.

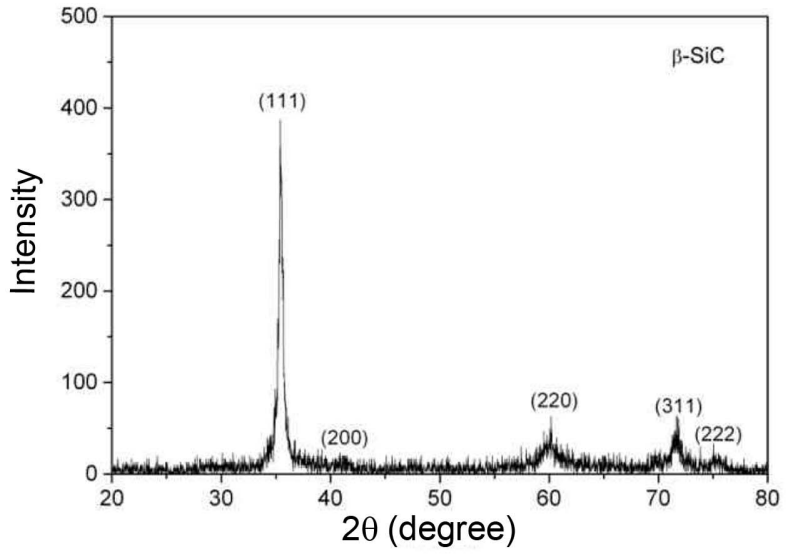

(a)

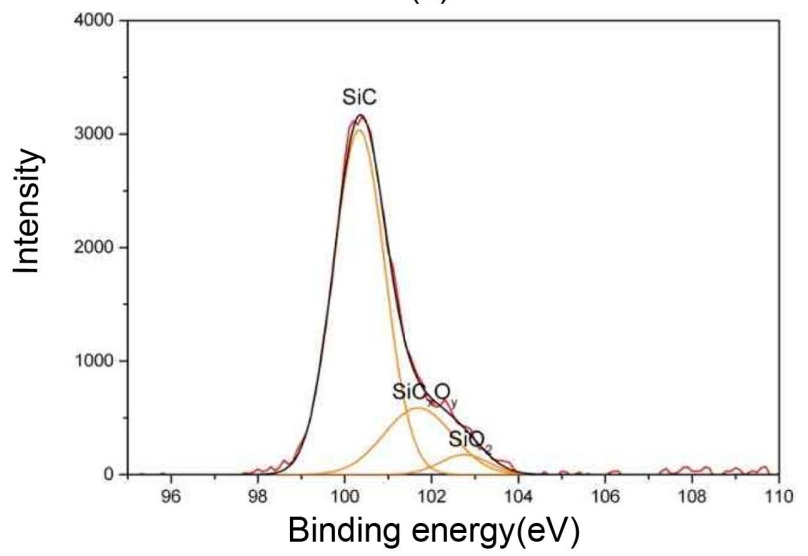

(b)

Fig. 4. (a) XRD and (b) XPS peaks for $\mathrm{SiC}$ matrix infiltrated at $1000^{\circ} \mathrm{C}$ and $\mathrm{a}=10$ for $15 \mathrm{~h}$.

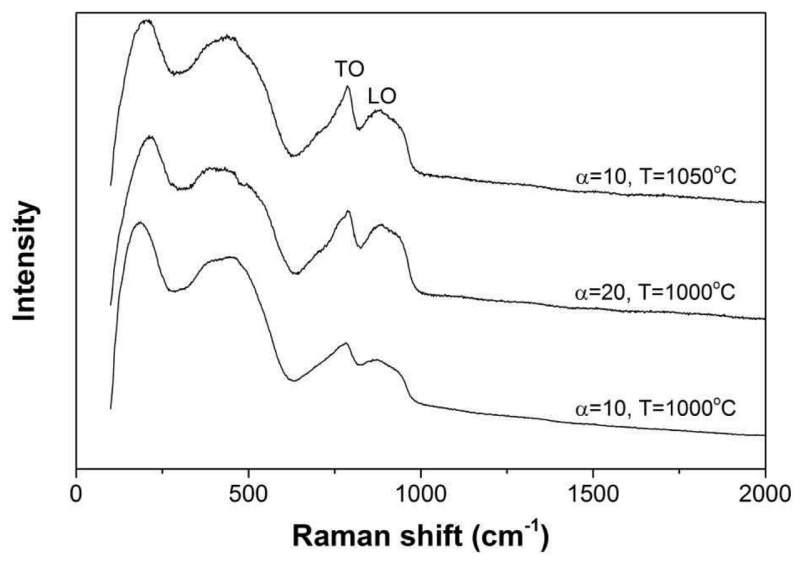

Fig. 5. Raman spectra of $\mathrm{SiC}$ matrix of a $\mathrm{SiC}_{\mathrm{f}} / \mathrm{SiC}$ composite layer infiltrated at $1000-1050^{\circ} \mathrm{C}$ and $10-20$ of $\mathrm{H}_{2} /$ MTS ratio.

Fig. 5는 온도 및 입력 기체비에 따른 $\mathrm{SiC}$ 기자상의 마 이크로 라만 피크의 변화를 보여 주고 있다. 모든 조건에 서 $\mathrm{SiC}$ 에 의한 $\mathrm{TO}$ 및 $\mathrm{LO}$ 라만 피크가 측정이 되어 결정 질의 $\mathrm{SiC}$ 가 침착이 된 것을 알 수 있다. $\mathrm{SiC}$ 의 피크는 결 
정립의 크기가 매우 미세하고, 적층 결함 등의 존재로 인 하여 피크의 퍼짐(peak broadening)이 관찰되며, 온도가 높 을 경우 피크의 퍼짐이 줄어 드는 것으로 나타났다. 또한, 온도 및 입력 기체비의 조건이 변하더라도 증착된 $\mathrm{SiC}$ 기 지상은 유리 $\mathrm{C}$ 에 해당하는 $1350 \mathrm{~cm}^{-1}$ 과 $1582 \mathrm{~cm}^{-1}$ 피크와 결정질의 유리 $\mathrm{Si}$ 에 해당하는 $521 \mathrm{~cm}^{-1}$ 피크는 측정 되지 않았다. 그러나, 비결정질의 $\mathrm{Si}$ 에 해당하는 약 $200 \mathrm{~cm}^{-1}$ 과 $450 \mathrm{~cm}^{-1}$ 부근의 넓은 영역에 걸쳐 피크가 관찰되고 있다 . 일반적으로 원료기체인 희석 기체비가 높아질 경우, 유리 $\mathrm{Si}$ 가 형성되는 온도가 더 낮아 질 수 있는 것으로 보고가 되고 있으며, ${ }^{19)}$ 비교적 낮은 온도인 $1050^{\circ} \mathrm{C}$ 이하의 온도 에서 높은 희석기체비의 조건에서 증착되었기 때문으로 판단되나, 정밀한 분석이 이루어져야 할 것으로 보인다.

\section{4. 결 론}

$\mathrm{MTS}$ 를 원료물질로 이용한 저압 화학기상법으로 CVD $\mathrm{SiC}-\mathrm{CVI} \mathrm{SiC}_{\mathrm{f}} / \mathrm{SiC}-\mathrm{CVI} \mathrm{SiC}$ 으로 구성된 가압경수형 원 자로의 삼중층 $\mathrm{SiC}$ 복합체 피복관을 제조하였다. 삼중층 $\mathrm{SiC}$ 복합체 피복관의 $\mathrm{SiC}_{\mathrm{f}} / \mathrm{SiC}$ 복합체 층 제조를 위해 필 라멘트 와인딩법으로 다양한 형태를 가지는 복합체의 섬 유 프리폼을 제조하였으며, $\mathrm{SiC}$ 섬유에 $\mathrm{CVD}$ 법으로 약 $200 \mathrm{~nm}$ 의 얇은 $\mathrm{PyC}$ 층을 코팅하고, 저압 $\mathrm{CVI}$ 법으로 $\mathrm{SiC}$ 기지상을 채워 넣었다. $\mathrm{SiC}$ 기지상 밀도는 섬유 부피 분 율이 낮은 6-return과 9-return 와인딩 패턴을 가진 샘츨에 서 가장 높게 나타났으며, 균일한 기지상 밀도를 얻을 수 있었다. 반면 섬유 부피 분율이 높은 1-return과 2-return 샘플은 침착 초기에 복합체층 표면 막힘 현상이 발생하 여 기지상의 밀도가 낮고 내부와 표면에서 큰 밀도 구배 가 크게 나타났다. $\mathrm{H}_{2} / \mathrm{MTS}$ 의 20 으로 증가시킬 경우 높은 섬유 부피 밀도를 가지는 복합체 프리폼에서도 기지상의 밀도가 매우 높게 나타났으며, $\mathrm{SiC}$ 내층과 $\mathrm{SiC}_{\mathrm{f}} / \mathrm{SiC}$ 복합 체층의 경계 부분에서의 밀도 감소는 관찰이 되지 않았 다. 그러나 $1050^{\circ} \mathrm{C}$ 이하의 낮은 온도에서 증착되었기 때 문에 비결정질의 $\mathrm{Si}$ 가 동시 증착된 것으로 나타났다.

\section{Acknowledgment}

이 논문은 2014년도 정부(미래창조과학부)의 재원으로 한국연구재단의 지원을 받아 수행된 연구입니다 (원자력 연구개발사업, No. 2012M2A8A5009818).

\section{REFERENCES}

1. J. R. Lamarsh and A. J. Baratta, Introduction to Nuclear Engineering; pp. 623-30, Prentice Hall, New Jersey, 2009.

2. Y. Katoh, T. Nozawa, and L. L. Snead, "Mechanical Properties of Thin Pyrolitic Carbon Interphase SiC-Matrix Com- posites Reinforced with Near-stoichiometric SiC Fibers," $J$. Am. Ceram. Soc., 88 [11] 3088-95 (2005).

3. H. Feinroth, M. Ales, E. Barringer, G. Kohse, D. Carpenter, and R. Jaramillo, Mechanical Strength of CTP Triplex SiC Fuel Clad Tubes after Irradiation in MIT Research Reactor under PWR Coolant Conditions; pp. 47-58, in Silicon Carbide and Carbon Composites, Vol. 30, Ceramic Engineering and Science Proceeding, Ed. by Y. Katoh and A. Cozzi, John Wiley \& Sons, New Jersey, 2009.

4. A. Kohyama, M. Kotani, Y. Katoh, T. Nakayasu, M. Sato, T. Yamamura, and K. Okamura, "High-performance $\mathrm{SiC} /$ $\mathrm{SiC}$ Composite by Improved PIP Processing with New Precursor Polymers," J. Nucl. Mater., 238- 287 565-69 (2000).

5. Y.-H. Ji, I.-S. Han, S. Kim, D.-W. Seo, K-S. Hong, and S.K. Woo, "Effects of Carbon Fiber Arrangement on Properties of LSI C $\mathrm{C}_{\mathrm{f}} \mathrm{Si}-\mathrm{SiC}$ Composites(in Korean)," J. Kor. Ceram. Soc., 45 [9] $561-66$ (2008).

6. J. Y. Park, S. M. Kang, L. H. Park, W.-J. Kim, and W. S. Ryu, "Effect of SiC Whisker Growing on Matrix Filling of the $\mathrm{SiC}_{\mathrm{f}} / \mathrm{SiC}$ Composite," Ceram. Eng. Sci. Proc., 24 [4] 613-20 (2003).

7. H.-W. Yu, K. Raju, J. Y. Park, and D.-H. Yoon, "Effects of $\mathrm{Al}_{2} \mathrm{O}_{3}-\mathrm{Re}_{2} \mathrm{O}_{3}$ Additive for the Sincerting of $\mathrm{SiC}$ and the Fabrication of $\mathrm{SiC}_{\mathrm{f}} / \mathrm{SiC}$ Composite(in Korean)," J. Kor. Ceram. Soc., 50 [6] 364-71 (2013).

8. J. Y. Park, M. H. Jeong, and W.-J. Kim, "Characterization of Slurry Infiltrated $\mathrm{SiC}_{\mathrm{f}} / \mathrm{SiC}$ Prepared by Electrophoretic Deposition," J. Nucl. Mater, 442 S390-93 (2013).

9. T. Koyanagi, K. Ozawa, T. Hinoki, K. Shimoda, and Y. Katoh, "Effects of Neutron Irradiation on Mechanical Properties of Silicon Carbide Composites Fabricated by NanoInfiltrated and Transient Eutectic Phase Process," J. Nucl. Mater., 448 [1-3] 478-86 (2014).

10. Y. Katoh, T. Nozawa, L. L. Snead, K. Ozawa, and H. Tanigawa, "Stability of $\mathrm{SiC}$ and Its Composites at High Neutron Fluence," J. Nucl. Mater., 417 [1-3] 400-05 (2011).

11. M. G. Jenkins and M. D. Mello, "Fabrication, Processing, and Characterization of Braided, Continuous SiC FiberReinforced/CVI SiC Matrix Ceramic Composites," Mater. Manuf. Process., 11 [1] 99-118 (1996).

12. D. Kim, J. Lee, J. Y. Park, and W.-J. Kim, "Effect of Filament Winding Methods on Surface Roughness and Fiber Volume Fraction of $\mathrm{SiC}_{\mathrm{f}} / \mathrm{SiC}$ Composite Tubes (in Korean)," $J$. Kor. Ceram. Soc., 50 [6] 359-63 (2013).

13. D. Cohen, S.C. Mantell, and L. Zhao, "The Effect of Fiber Volume Fraction on Filament Wound Composite Pressure Vessel Strength," Compos. PART B-Eng., 32 413-29 (2001).

14. E. V. Morozov, "The Effect of Filament-winding Mosaic Patterns on the Strength of Thin-walled Composite Shells," Compos. Struct., 76 123-29 (2006).

15. S.-D. Liang, F.-Q. Zhang, L.-H. Xia, Q. Yu, and X.-Y. Zhang, "Effect of Preform Structure on Densification Process of Plate C/C Composite," Mater. Sci. Eng. Powder Metall., 17 [2] 252-7 (2012).

16. X. Hou, H. Li, Y. Chen, and K. Li, "Modeling of Chemical Vapor Infiltration Process for Fabrication of Carbon-Carbon Composites by Finite Difference Methods," Carbon, 37 
669-77 (1999).

17. B. Reznik, D. Gerthsen, W. Zhang, and K.J. Hüttinger, "Microstructure of SiC Deposited from Methyltrichlorosilane," J. Eur. Ceram. Soc., 23 1499-508 (2003).

18. D. Kim, W.-J. Kim, J.-E. Jang, S. G. Yoon, D.-J. Kim, and J. Y. Park, "Oxidation of CVD $\beta$-SiC in Impurity-controlled
Helium Environment at $950^{\circ} \mathrm{C}$ (in Korean)," J. Kor. Ceram. Soc., 48 [5] 426-32 (2011).

19. J. Chin, P. K. Gantzel, and R. G. Hudson, "The Structure of Chemical Vapor Deposited Silicon Carbide," Thin Solid Films, 40 57-72 (1977). 